\title{
电子信息工程的具体运用及发展
}

吴姣

百色市科学技术情报研究所

DOI:10.18686/bd.v2i1.1186

[摘要] 在二十一世纪信息化时代,电子信息网络技术得到了突飞猛进地发展,电子信息职业开始在我国各个领域中有所 渗透,逐渐在我国国民经济发展过程中发挥着至关重要的作用, 极大地推动了各类行业的共同发展。目前, 电子信息工程早已 在各行业中得到了广泛性的运用,为此,本文针对电子信息工程在社会中的具体运用进行相关论述,同时针对电子信息工程 的未来发展做出了系统性的介绍。

[关键词] 电子信息工程;运用; 发展

\section{1 电子信息工程的概述}

电子信息工程是利用现代化计算机技术实现了对电子 信息的相关操作与具体处理。对规划运用系统和相关电子 设备等进行研讨, 根据实际需求对信息进行收集与处理,并 且能够完结设备与系统的规划性研发与集成, 在那个时期, 网络编程、模仿数字信号间可实现成功地转化,利用通讯这 一基本原理为电子信息技能的现代化创造良好的基础条 件。在各行各业当中,电子信息工程获得了广泛化的运用,这 在一定程度上推动着我国其他行业的进步与发展。

\section{2 电子信息工程的具体运用}

2.1 在工程造价管理中的运用

网络通讯管理平台是工程管理过程中电子信息工程运 用的直接体现，其是利用先进的信息技术对工程实施的技 术化管理,从而实现自动化办公的效果,促使当前的工程管 理水平得到显著性的提高,提高当下办公效率。利用计算机 软件进行工程钢筋使用数量及相关工程量的具体计算, 从 而可为工程造价预算与决算供应科学合理的编制依据。在 信息系统的运用上,可通过创建信息指标体系的方式,为工 程建设提供充分的服务。在信息时代下,电子信息在整个工 程管理中的作用逐渐凸显出来, 并且也获得了显著性的不 断发展，人们可利用先进的信息技术来做好工程造价的全 过程掌控或进行标底的编制, 从而促使工程管理信息化的 顺利实现, 从而促使所有的工程管理软件得到深层次的开 发及广泛运用。在现代化信息网络技术迅速发展的基本现 状下, 各类工程项目造价与工程管理活动所供应的信息服 务网站在数量上呈现出持续上升的发展趋势, 这些信息网 络为工程提供了相应的法律规章制度、相关信息的价格等 内容, 从而为工程造价管理工作的开展提供了强有力的信 息支持。

2.2 在农业机械中的运用

从目前我国农业的发展现状来看,网络化、智能化及数 字化是现代化农业发展的显著标志, 而引起此发展现状的 主要根源在于现代化电子信息技术的发展所造成的, 从而 推动我国农业向机械化的方向迅速发展。目前,现代机械化
农业早已成为一个独立性的信息系统，同时可对信息进行 综合性的智能化处理。要知道,一台大型复杂的设备能够实 现对多个电子标准控制原件的顺利安装, 微型作业计算机 不仅使用的是标准统一的端口, 同时会把局域网控制技术 很好地运用起来。由此可见,电子信息工程的有效运用在一 定程度上促使我国农业固有的发展模式发生了根本性的转 变,推动我国农业向现代化的方向快速发展。

2.3 在常用设备中的运用

在信息化技术迅速发展的基本现状下，电子工程技术 给我们的日常生活、生产带来的影响力逐渐显著, 并且, 电子 信息工程开始不断地融人到我们的日常生活及生产范围当 中, 譬如: 数字电视网络、空调制冷系统、电冰箱恒温系统的 控制等等, 都可以看出电子信息工程对我们日常生活带来 的一系列显著性影响。譬如:一辆汽车,组成其电子控制单 元能够单独地完成相关方面的系统性操作, 同时可实现彼 此间的协调, 从而促使汽车在最佳的状态下正常运行; 又 像: 电梯,电子在正常使用的基本原理上进行了电子信息系 统的安装, 可促使其达到自动化、智能化运行的效果, 使得整 个运行设备得到整体性的优化, 促使其运行效率得到显著 性的提升。

\section{4 在公路工程的运用}

通常施工工艺复杂、工期较长是公路工程施工存在的 显著特征, 从而造成公路工程中存在非常多的数据,在此期 间, 需进一步对工程施工进度、施工质量及施工成本进行实 时性更新与合理性的有效掌控, 有效地利用电子信息工程 技术, 从而促使工程在人力、物力方面的资源大大减少, 为 此, 现代化信息工程在目前我国公路工程管理中的运用范 围越来越广泛, 在一定程度上推动着我国公路工程建设向 现代化的方向不断发展。

\section{5 在教育中的运用}

在人类步人到信息化社会的基本现状下，信息化教育 成为关乎整个人类社会进步的巨大力量。通常情况下,信息 化教育是指电子信息工程技术在教育过程中有效运用的一 种教育方式, 将先进的计算机网络技术在日常教学中加以 
有效运用。信息化教育不但是为了更好地迎合信息时代环 境下对信息的基本需求，同时在某种程度上推动着人类信 息社会的进步与发展。要知道,电子工程技术与教育之间有 着非常紧密的联系性, 可以说, 网络技术的发展最根本的起 源在于教育。目前,在很多学校里都相继进行了电子信息专 业的课程设置,开始对于学生的获取信息、采集信息、分析 信息及加工信息等方面的能力进行了侧重性培养, 开始实 施计算机网络教学这一全新的教学模式, 从而为我国信息 化教育教学工作的开展奠定了良好的基础。

\section{3 推动电子信息工程发展的策略}

3.1 政府加大扶持力度

伴随着电子信息工程的不断发展, 国家政府部门开始 处在了引导的重要地位, 然而, 政府部门这一关键的引导者 的作用是否能够真正地发挥出来, 对整个信息工程的未来 发展有着直接性的影响。对此,政府部门要不断地增加电子 信息项目建设力度, 提高在电子信息技术研发方面的成本 投人力度,不断地拓展电子产业投资渠道,制定科学合理的 电子信息工程技术创新方面的政策支持, 队电子信息工程 技术的创新成果给予肯定和相关奖励,与此同时,创建电子 信息工程基金, 为电子工程的未来可持续发展奠定坚实的 资金保障,作为引导者,国家政府及相关单位要不断地加强 信息通信技术、多媒体技术等网络科学技术的研发,从而更 好地推动我国电子信息产业得到更好地发展。

3.2 培养专业型人才

在电子信息系统当中人才发挥着至关重要的作用,是 发展电子信息工程的关键所在。再发展我国电子信息工程 的过程当中要牢牢坚持“以人为本”的基本发展理念,重视 专业技术人才的培养, 要知道, 只有拥有一支具有高技术水 平及综合素质的人才团队, 才能够推动我国电子信息工程 得到强有力地发展。此外,电子信息工程要不断地增加在人 才培养方面的资金投人,进一步完善人才激励制度,从而为 人才的未来发展创造良好的环境。同时各大院校要开设电 子信息专业, 从目前的社会发展情况出发,不断地融人先进 的科技信息只是, 定期开展信息专业人才的系统性培训,这 样才能够为社会培养所需要的专业技术人才。

3.3 加快电子行业的创新

现代化社会是一个信息化时代,在此期间,电子产业市 场发生的变化是十分迅速的,在这一发展环境下,我国电子
行业亟待需要进行不断地创新,其中,在电子信息工程的运 用及产品的创新上, 加强产品的不断更新与系统性升级, 对 此, 电子企业要不断强化对电子信息技术的改造与创新,并 且加强与其他企业间的沟通与有效协作, 在电子信息工程 向国际化方向不断发展的现状下, 实现先进科学技术与产 品进行不断地研发与创新。

\section{4 增强知识产权的保护}

在电子信息工程发展方面, 增强知识产权的系统性保 护具有十分重要的意义。目前,我国不少的科研人员在技术 研发方面获得了显著性的成就。可是,受到自身知识产权保 护意识较低的影响, 有不少的可言技术成果却被他人盗取, 从而在告诫我们, 一定要加强对知识产权的系统性保护, 从 而促使知识产权相关知识得到较大范围的普及, 同时使得 科技人员的知识产权保护意识得到进一步提高。与此同时， 国家相关政府部门要不断地强化知识产权法律保护力度, 严格认真执法, 创造出良好保护意识的社会信息发展环境, 做好研究工作人员研究科技成果保护措施, 促使大家的工 作积极性得到显著性的提高，维持科研者的创造热情。

\section{4 结语}

虽然,电子信息工程技术在我国发展时间比较短,可是, 其整体却有着非常高的实用价值,可以说,电子信息工程的 发展将会在一定程度上推动整个社会的巨大进步。目前来 看,在我国的日常生产、居民生活、航空、工农业等方面电子 信息工程技术都获得了广泛性的运用, 伴随着其不断创新 与研发,将会运用在更多领域当中,本文通过对电子信息工 程的具体运用及发展的论述, 望能够对今后电子信息工程 的运用上起到一定的可参考价值。

\section{参考文献:}

[1] 郭宵.自动化技术在电子信息工程设计中的运用分 析 [A].新教育时代(2015 年 11 月总第 6 辑) [C].2015:1.

[2]朱思佳,潘阳,刘爱慈.电子信息技术的运用特点与未 来发展[J].通讯世界,2016,(07):280.

[3]王冲. 计算机网络在电子信息工程中的运用 [J]. 赤 峰学院学报(自然科学版),2015,(14):20-22.

[4]张夫.关于发展电子信息工程技术的探析 [A]. 天津 市电子学会. 第二十九届中国 (天津) 2015' IT、网络、信息技 术、电子、仪器仪表创新学术会议论文集 [C].天津市电子学 会,2015:3. 